\title{
Academic Self-Regulation on Students with Attention Deficit Disorder with or without Hyperactivity: Parents' and Educators' Point of View
}

\author{
Mairi Giannopoulou \\ Special Education Needs, Metropolitan College in Collaboration with University of East London, Athens, Greece \\ Email: magiannopoulou92@gmail.com
}

How to cite this paper: Giannopoulou, M. (2019) Academic Self-Regulation on Students with Attention Deficit Disorder with or without Hyperactivity: Parents' and Educators' Point of View. Open Journal of Social Sciences, 7, 97-110.

https://doi.org/10.4236/jss.2019.78008

Received: July 12, 2019

Accepted: August 13, 2019

Published: August 16, 2019

Copyright () 2019 by author(s) and Scientific Research Publishing Inc. This work is licensed under the Creative Commons Attribution International License (CC BY 4.0).

http://creativecommons.org/licenses/by/4.0/

\begin{abstract}
This paper aims to highlight the ways that students with Attention Deficit Disorder with or without Hyperactivity use for their academic self-regulation. The reasons that motivate students to specific reactions and behaviors during their schooling, both at school and at home are examined in detail. A basis is given to special educators' and parents' actions in order to present the implemented actions to enhance academic self-regulation.
\end{abstract}

\section{Keywords}

Attention Deficit Disorder with or without Hyperactivity, Academic Self-Regulation, Parent-Teacher Actions, Special Education Needs or Disabilities, Integration, Self-Regulating Learning, Autonomy

\section{Introduction}

Students with special educational needs or disabilities have significant behavioral deficits, which affects their general integration into any community. However, according to scientists, self-regulatory skills can be taught and can effectively help people with disabilities [1]. Self-regulating learning gradually has to be a high priority in the educational process as it has many benefits. Research shows that children not only improve their academic performance, but also strengthen socially [2]. Autonomy and independence from teacher and parent guidance is also an important achievement of self-regulating learning as it contributes to the self-identification of the individual.

Attention Deficit Disorder (ADD) and Hyperactivity Disorder (ADHD), 
known in the international literature as Attention Deficit Hyperactivity Disorder (ADHD), is classified to neurodevelopmental disorders [3]. The first to study the disorder was Still (1902) and Tredgold (1908), mainly observing small groups of hyperactive children. Since the 1980s, the disorder has been the subject of a more systematic study and it is confirmed that it is a neurodevelopmental disorder with a possible genetic basis, which is also affected by environmental factors.

ADHD is characterized by a range of difficulties in focusing, controlling, and restraining, and is likely to be accompanied by hyperactivity in a degree and duration that is inconsistent with the biological age of the individual. In addition, it is directly related to difficulties in internal and external self-regulation, rhythm, audiovisual perception, short and long-term memory, as well as perceptual alertness.

The disorder has three forms: 1) ADHD with predominant the careless type, which is equally found among boys and girls, 2) the ADHD with predominant the hyperkinetic type, which occurs mainly in boys and c. the combined type [4]. Clinical symptoms may be starting from infancy, as babies seem to have hypersensitivity to stimulation, intense kinetic activity, cry more and sleep less hours.

In the field of self-regulating learning, many studies for pupils with special educational needs and disabilities have taken place. Most of them refer to children with learning disabilities. The students of our country do not differ significantly in their self-regulatory capacity in relation to foreign students [5]. The differences that arise are due to the Greek educational system, which does not promote the self-regulatory skills to people with disabilities [6].

Through self-regulation, learning objectives are considered to be more effective as incentives, as they focus on help, feedback, autonomy, and have more interesting activities [7]. Interventional self-regulatory programs in people with attention deficit disorder/ hyperactivity, learning difficulties, behavioral disorders and autism spectrum disorders have been successful [8].

It is worth mentioning surveys conducted in Greece, comparing students with mental and kinetic disabilities with self-image and self-regulation. Pupils with a mental disability had a positive self-image and regulated their behavior, in contrast to students with kinetic disabilities [9].

In addition to 2012, Nader-Grosbois \& Veiellevoye conducted a survey of the differences in self-regulatory strategies in 40 children with mental disabilities and 40 with typical development. Children with mental disabilities had difficulty in identifying the target, but there have been no difficulties in planning and attention.

Academic self-regulation using self-management techniques is also an effective method for autistic people to enhance their social interaction, while reducing their dependence on the presence of the teacher [10].

In fact, studies done in children with neurodevelopmental disorders demonstrate that self-regulatory strategies achieve the generalization of positive behaviors in a variety of environments [11]. 
Given the recent emphasis on the co-education of pupils with special educational needs and disabilities and students of typical development, the value of self-regulation techniques is more underlined. Surveys show that through self-regulation, integration into school achieved easier, a key issue of modern reality.

Awareness of the importance of self-regulatory education given by teachers and their support in this area can provide more opportunities for skills development. Wide acceptance of these skills positively affects the extent to which they choose self-regulatory strategies for pupils with disabilities, regardless of age and special educational needs.

However, despite the number of studies and the emphasis given on autonomy through self-regulating learning, self-regulation and strategies do not refer to current curricula. It is also proven that self-regulation should be promoted from early childhood so that individuals have acquired some behavior management strategies before starting school [12].

In conclusion, it is clear from scientific studies that self-regulation education is crucial for people with disabilities regardless of age and educational needs or disability.

\section{Ease of Use}

\section{Theoretical}

The term of academic self-regulation or self-regulated learning emerged in the 1980s to investigate how students engage themselves in their own learning process. As Zimmermann says, "self-regulation is not a cognitive ability nor a skill linked to academic performance, but rather referred to as a self-directed process through which students transform their mental capacities into academic skills related to a particular context activities" [13]. In recent years, teachers increasingly prefer pupil-directed learning [14]. Students are actively involved in the learning process, set goals, select enhancers, record and evaluate the whole process. The main goal of academic self-regulation is to achieve the autonomy of students who are able to self-regulate their behavior and react to events, achieving self-determination. Zimmermann, in order to understand the link between self-regulation and internal motivation, developed the "circular model", which consists of three stages: 1 ) the forethought, 2) the executive (volitional/performance control) and 3) the reflection stage. At the forethought stage the learner activates his/her previous knowledge and motivations, sets personal goals and designs the method for achieving them. In the "executive", trainees through self-control engage in learning activities by recording their progress and experimenting with alternative strategies. At the reflection stage, the student is self-evaluating and either receives positive responses or redefines the goals [15]. Self-regulatory strategies are as follows: 1) self-recording or self-monitoring, 2) self-assessment or self-evaluation, c. self-reinforcement d. self-instruction and e. goal-setting. 


\section{Method}

\subsection{Research Design}

The method chosen in this research is the qualitative method, which focuses and answers the questions "how" and "why", while providing flexibility in the process. Every qualitative researcher is studying things in a natural context for the understanding and interpretation of phenomena. The researcher's view, which emphasizes on the qualitative, non-measurable characteristics for interpreting, understanding, developing, confirming or refuting a theory or revealing causal relationships, plays a decisive role.

Qualitative research helps to explore issues that are first approached or insufficiently explored. Unlike the conceptual predetermined specifications of quantitative methods, in qualitative methods, each researcher can approach a subject without having predefined perceptions of the variables, thus leading to the construction of a theory about the explanation of the subject. The qualitative researcher organizes the information he collects building key concepts and then removes some of them. The aim is to build a satisfactory set of topics and modules that will respond satisfactorily to the research questions that have been set at the beginning of the survey.

The most important thing in qualitative research is that the researcher should collect as much information as possible on the issue of interest, which is achieved with flexibility, sensitivity to the approach and flexibility in collaborating with the subjects.

In this research, an interview was used as a research tool for teachers and parents of children with Attention Deficit/Hyperactivity Disorder. This method involves the gathering of information through direct verbal communication of the researcher with the subjects, assisting the in-depth learning of information, compared to other methods. Respondents are asked to answer a series of questions. Through their answers, the researcher discovers their relationship to the research object compares or groups their views.

The interview with other research tools offers direct and personal communication, and research questions are explored in depth. This is because people prefer to talk rather than write, especially when it comes to personal data that require a relationship of trust between the researcher and the respondents. In addition, it is important to obtain information that can only be secured by personal communication, such as the observation of behavioral reactions, tone of voice and gestures.

In this survey, a semi-structured interview with special education educators and parents will take place in order to collect data on the self-regulation of children with $\mathrm{ADHD}$ and the actions undertaken to develop self-regulatory skills.

In the semi-structured interview, the researcher has a list of questions to be answered by the participants, but at the same time the discussion may evolve differently according to the answers to be given. The researcher can ask for cla- 
rifying questions in order to get as much information as possible.

The interviews take place individually, in the parents' free time and in their personal space. The research is based on Academic Self Questionnaire (SRQ-A) performance, according to which the interview was structured. The scale of academic self-regulation consists of four basic questions with eight sub-questions each. Interview questions are open-ended that will allow participants to freely develop their answers without predefined frames.

\subsection{Sample Participants}

In the present work, ease of sampling (facilitation or convenient) will be used in which respondents are selected to respond to researchers. Specifically, interviews will be answered by 10 special educators from various sectors of special education (speech therapists, occupational therapists, psychologists, parallel support teachers, primary and secondary educators) and 10 parents of children with Attention Deficit/Hyperactivity Disorder. Two-thirds of the respondents were women, while the predominant age range of the total population was from 30 45 years.

\subsection{Research Tools}

In this research, an interview was used as a research tool for teachers and parents of children with Attention Deficit/Hyperactivity Disorder. This method involves the collection of information through direct verbal communication of the researcher with the subjects, assisting the in-depth learning of information, compared to other methods. Respondents are asked to answer a series of questions. Through their answers the researcher discovers their relationship to the research object, compares or groups their views. The interviews take place individually, in the parents' free time and in their personal space. The research is based on the Academic Self Questionnaire (SRQ-A), according to which the interview was structured. The scale of academic self-regulation consists of four basic questions with eight sub-questions each. Interview questions are open-ended questions that will allow participants to free develop their answers without predefined frames.

The four basic questions of the academic self-regulation are why they study their homework, why they participate in class, why they try to answer difficult questions and finally why they try to keep up at school. The sub-questions of the scale demonstrate the reasons why a child with ADHD is studying at home to enhance his/her physical presence in the classroom as good as possible by helping the reader to have a complete picture of the student with that particular disorder. The researcher thus evaluates the internal motivation to achieve academic self-regulation on the part of the student himself.

\subsection{Validity and Reability}

In the present study, in order to ensure reliability, the triangulation method was 
used. In this way, data from different sources were cross-checked to confirm or reinforce each other. Each data source was linked to each research question, giving the essentials to the researcher. More specifically, interviews with parents of children with ADHD have been triangulated with each other and with the interviews of specialist teachers, which were equally triangulated with each other. Each data source, therefore, complemented the analysis by giving credibility to the results of the research and ensuring adequate answers to the research questions.

\subsection{Research Questions}

Self-regulating learning has to be a high priority in the educational process as it has many benefits. Research shows that children not only improve their academic performance, but also strengthen socially [2]. Autonomy and independence from teachers' and parents' guidance is also an important achievement of self-regulating learning as it contributes to the self-identification of the individual.

The method of academic self-regulation can be applied to special education, for most areas of special needs and disabilities. The present study will assess how children diagnosed with Attention Deficit Disorder with or without Hyperactivity (ADHD) regulate their behavior and their degree of autonomy in the classroom, given their neurodevelopmental disorder characterized by a lack of self-control, behavioral and organizational problems, and inability to maintain attention and focus. The main question is the degree of their response to the requirements of the cognitive subject, through the actions of self-management of their behavior.

The bibliographic review reveals a series of queries, which are a question of the research process, in order to fully understand the concept of academic self-regulation and to emphasize the crucial role of teachers and parents in its implementation. These questions are as follows:

1) What are the reasons why a child with Attention Deficit/Hyperactivity Disorder studies his home lessons?

2) What are the reasons why a child with Attention Deficit/Hyperactivity Disorder participates in classroom lessons?

3) What are the reasons why a child with Attention Deficit/Hyperactivity Disorder tries to do well at school?

4) How internal motivation to achieve self-regulatory academic self-regulation of Children with Attention Deficit/Hyperactivity Disruption is evaluated?

5) What actions do special educators implement to develop self-regulatory skills in children with Attention Deficit/Hyperactivity Disorder?

6) What actions do parents implement to develop self-regulatory skills in children with Attention Deficit/Hyperactivity Disorder?

\section{Data Analysis}

Teachers completed the Academic Self-Regulatory Questionnaire (SRQ-A). The 
questionnaire consists of 4 basic queries with 8 sub-questions each marking their responses to the Likert scale as each proposal represents each of them from "Absolutely True" to "Not at all True". Then, the teachers responded to semistructured interview questions based on the above scale. In a semi-structured interview, the pupils' parents also responded in space and time that they themselves chose, having been informed in detail about the purpose of the survey, the necessity of their participation and having ensured the anonymity and protection of their sensitive personal data.

\section{Results}

\subsection{Research Question 1}

The question "Why a learner with Attention Deficit/Hyperactivity Disorder studies homework lessons" which is related both to the internal and external self-regulation of students, shows that their learning interest is reduced due to a variety of factors. The duties undertaken are rarely accomplished, either due to a lack of organization, or due to deliberate or non-resignation. Many teachers say that the failure to complete the school project is a common phenomenon, but they conclude that this is directly related to the difficulties that the disorder itself presents. Various environmental stimuli, as well as rapid interest rotation often distract students from the study. The feeling of reduced self-esteem is related to what has been mentioned above, as the mental potential of children with ADHD allows them to perceive their weakness, leading to denial or avoidance of tasks, as they easily lose their self-confidence. Often, as the opinion of others seems to be of great concern to them, they even pretend health reasons for failure or miss to complete their work. The most "impulsive" children, in fact, show aggression in case of cancellation. Concluding at this point with the views of the teachers, the opinions of the parents of students with ADHD are also given. Parents confirm the fact that their children rarely carry out on a day-to-day basis their school responsibilities for the next day autonomously. If their study is undertaken by a specialist pedagogue or a study center, they consider work to be more likely to be completed. However, either independently or with the help of someone else, they do not show any particular desire for a school study. In addition, parents confirm that their children often go unprepared to school, as they often show a persistent refusal to study.

\subsection{Research Question 2}

Children with ADHD in their classroom image are disruptive and abstract, often painting and talking to their neighbor. They usually forget their notebooks and books, and in the course they are too active or completely indifferent. More generally, they have the image of a "restless and anxious child" that is constantly in an unacceptable movement in that particular environment. They are easily distinguished by noises or smells, they are impatient, they do not wait for their turn and generally do not comply with the rules of the class. Often they even try 
to make "out of pace" and their classmates, taking them away. Socially and communicatively they are either fully dear to their classmates or fully disliked, as they often speak abruptly and do not restrain their thoughts by bringing others into a difficult position. Taking into account the above descriptions of the teachers as they emerged from the semi-structured interview, it is easy to understand that the degree of their participation in the classroom is modest. Certainly when a topic or a lesson motivates their interest or they find it entertaining their level of participation is higher. The pupils' participation during school time is again linked to the image students want their teachers to have. If they take an oral comment or if the teacher shout at them, they feel ashamed of themselves. On the contrary, after being as active as possible, they feel proud and their self-confidence is growing. Parents report that their children in the school environment are negative, mainly because of their behavior which does not allow them to participate as they should. Their impulsive and often challenging behavior pre-empowers the teachers, leading to the result that they have misperceptions about the student with ADHD.

\subsection{Research Question 3}

By analyzing the results of the SRQ-A scale, it is clear that students with ADHD are interested not only in the image that teachers have for them but also their classmates. This is also their main motivation for their progress in school. By associating their social acceptance with their school performance, they often try to answer difficult questions during the lesson, because they will be called "smart" or receive a positive comment that will stimulate their self-esteem. Sometimes, however, they rarely respond to difficult questions, as they cannot manage the frustration and embarrassment they will feel in the event of a wrong answer. According to the parents' comments, as soon as their children are confronted with demanding or difficult questions they usually resign before they even try or start and quit in a short period of time. Parents believe that they are driven to this by an intimate matching of school performance with their social image. Sometimes they even break out, get angry, or even leave the room, wanting to avoid the answer that will ridicule them.

\subsection{Research Question 4}

By isolating the internal motivation to achieve academic self-regulation in this question we see that there is a convergence of educational views that children with Attention Deficit Disorder do not have fun studying at home and present little excitement lessons. They are forced to study mainly to avoid any problems that will arise in the room, or a bad comment from their teachers. Students with ADHD use their participation in the lesson and try to solve difficult questions not as a motive for their acquirement new knowledge but to avoid being ridiculed in front of other people if they seem unready for the course or do not know how to answer a question. It is common for a child to avoid difficult questions due to a resignation because of a poor self-image of their personality. An 
exception is a lesson that will stimulate their interest and will converge with their interests, which will surely find more fun and will decide to do more about it. The fact that school performance affects his/her psychology and self-esteem affirms that students with Attention Disturbance disorder knowing their weaknesses generally do not enjoy the learning process and easily lose self-esteem as soon as they fail. Complementing the above, it is also evident from parents' interviews that school performance directly affects child psychology and behavior. Children with ADHD are characterized by low self-esteem and often go to negative self-assessment. This fact often forfeits their motivation for study. In particular, they are indifferent or have a refusal because they think in advance that they will fail. It has been reported that often because of weaknesses in their general organization they do not fully correspond to tasks and tasks. Even when they are consistent with their obligations, they seek immediate reward, otherwise they are deeply frustrated, disappointed, and completely abandoning every effort. A low grade, a punishment at school and a much worse a repetitious examination of a lesson, affect the psychology of ADHD children, "hitting" their self-esteem. The failure to manage failure often causes tension that manifests itself in a variety of ways.

\subsection{Research Question 5}

Taking into account the difficulties faced by students with ADHD in completing their work and the general participation and expression of their feelings, teachers were asked to refer to the actions they take to develop the skills of the academic self-regulation of their pupils. In order to promote their participation, teachers form the school environment in order to reduce the disruptive elements that will disintegrate the child. They usually choose to put the children in the first desk near their chair to have direct eye contact with it. They also assign roles of responsibility, for instance, erase the board, carry the notebooks to the headquarters for the teacher to correct them, etc., that make them feel great and responsible. This undoubtedly serves as a positive incentive for internal self-regulation and gives students a sense of personal satisfaction and self-esteem. Indeed, when students assume these roles most of the time they are performing with immense success.

\subsection{Research Question 6}

Parents, understanding their children's inability to organize and manage their daily program, define a specific program to help their children know when to study for school and when they have free time to dedicate to what they love. This program is combined with rules, which, if infringed, children are subjected to a quick punishment in order not to repeat the unwanted behavior.

\section{Discussion}

After the settlement of the research process, we find that there are many points where the opinions derived from the questionnaires and the interviews are con- 
verging or even identifying. Teachers' Self-Efficacy can be considered as a key parameter in dealing such problems [17]. Initially, it is clear that students with Attention Deficit Disorder with or without Hyperactivity are characterized as abstract and disruptive, disorganized and often deviating from their learning tasks. As far as their school obligations are concerned, they do not formally complete their schoolwork as they are easily degraded by a variety of environmental stimuli or resign easily when faced with some difficulty in completing the job. The motivation is the praise of parents and teachers, and there are not many times when the whole process is necessarily completed in order to avoid tensions or consequences, for example, depriving their favorite object or forbidding something that pleases them. Parents wanting to prevent the inconsistency of their children against their school obligations are addressed to special educators or study centers. Regarding their participation in the classroom, they show a selectivity that depends on the extent to which their school activity motivates them. If they feel inertia, they get distracted, they move more than usual or start to disturb the other children. When students have not completed their work or have not studied their lessons they try not to reveal themselves. If they cannot achieve it, they use excuses, or they invoke health reasons. Other times, they respond with humor or in a provocative way because they want to draw the teacher's attention to their behavior to deal with it and not with their inconsistency. Although they display a low degree of typical behavior, they are interested in the image that teachers will have about them. They often try to answer tricky questions to make them look smart to the others. The positive view of teachers and classmates greatly stimulates their self-confidence. Students' self-esteem also seems to be linked to their performance at school, which is inextricably linked to the psychology and behaviors they develop. Strong bonds among teachers and classmates can bring spectacular results to pupils' school performance. Conversely, whenever a student with distraction or hyperactivity fails, he is frustrated and leads to a variety of reactions. Not only behaviors such as anger or provocation, but also the development of feelings of low self-esteem, anxiety and refusal or easy surrender of each project is common. They experience intense frustration resulting in hyperactivity, irritation, tension and finally the explosion.

\section{Conclusion}

In the first research question, "What are the reasons why a child with Attention Deficit/Hyperactivity Disorder studies their lessons at home", it is obvious that due to reduced learning interest, lack of organization and resignation associated with the disorder itself, students rarely complete their schoolwork. Parents confirm the fact and, in order to help, they appeal to study centers and special educators to guide their children in their daily study. Students with ADHD will be led to study to avoid tension with their parents and mostly the fear of not being deprived of their favorite occupation, and it is obvious that they do not find 
studying at home interesting at all. In investigating the reasons why a child with distraction tries to participate in the classroom class, teachers consider that participation is mediocre, as soon as the learning subject expresses the interest of the student or considers it entertaining. The pupils show interest in the teacher's image of their participation, as if they receive an oral comment, they feel ashamed. Their shame is sometimes manifested by resignation and others with extreme impulses [16]. However, it is obvious that the confrontation and restoration of the pupil when he/she is distracted, it must be particularly careful. In addition, we must keep in mind that the very nature of the disorder is inhibiting the proper functioning of school participation and action. The main motivation for their good performance at school is the image that others will have. Students with ADHD connect good school performance with their social acceptance. Many times the impulse that distinguishes them makes them less socially sympathetic. A good comment from the teacher stimulates their self-confidence, while frustration is a reason of poor school performance and refusal. Teachers, who are aware of the difficulties faced by children with ADHD in their academic self-regulation, use various actions to support them. Besides, this is the educators' role, to choose the appropriate learning strategies that will help their pupils individually. Once teachers are confronted with the "ordinary", as they describe the phenomenon of incomplete school exercises and study, they use the encouragement and reinforcement to make the work happen next time. Also, when it comes to a demanding question that makes it difficult for students they simplify the question. Using precise and simple vocabulary explains the exercise; they distinguish the different requests and with appropriate questions lead their students' thoughts to the correct answer. Student guidance is done through visualization using different underline colors or cards tailored to the needs of each student. In addition, individual exercise in school activities helps children organize themselves in their program, remember rules and instructions, self-control, and ultimately improve their weaknesses. Teachers often use roles to engage with the child by fostering self-confidence. Very helpful is the proper construction of the space, free of disruptive elements and the placement of the pupil on a desk near the teacher's seat. These intervention strategies have proven to be catalytic for the progress of children with ADHD as they offer models of imitation, self-assessment and self-improvement. When students experience a state of frustration or anger, their teachers identify the negative stimulus and try to distract them and do something else. Methodically they recall the rules of classroom with calm voice and fixed tone. Once the student calms, they give him the opportunity to talk about what led him to this behavior, helping him criticize his behavior. Then, similar solutions are proposed to help him regulate his behavior and prepare himself in a similar situation. In some cases, decongestion and expansion are necessary. As shown by parents' interviews, the latter rely on their close cooperation and briefing with teachers, which of course requires openness and flexibility on both sides. Parents follow the actions of teachers to strengthen 
self-regulation of their children. They spend more time on their children, trying through discussion and admonitions to help them by respecting their peculiarities [18]. Parents also strive to reduce the disruptive stimuli of space, as much as possible in the home environment. Parents focus mainly on stimulating their children's self-confidence through their praise and constant support. Finally, particular attention should be given to the impact of academic self-regulation on the social and emotional education [19] and self-regulation of children with ADHD. Even though they sometimes make punishments, they are only meant to put an end to a particularly negative behavior. Even though they sometimes make punishments, they are only meant to put an end to a particularly negative behavior [20].

\section{Study Limitations}

As stated, the purpose of the research was to investigate how students with ADHD regulate their behavior in order to cope with the different areas of their school reality in the light of the actions implemented by both school teachers and parents promoting academic self-regulation.

During the survey a number of suggestions emerged that could be used for future research. Initially, the negative impact of punishment by teachers and parents on the psychology of students with ADHD and the alternative use of methods of stopping negative behaviors in case they do not meet school requirements and their academic self-regulation could be explored. In addition, it would be particularly interesting to explore the self-image of the student with ADHD in conjunction with their classmates' views on it. Finally, particular attention is given to the impact of academic self-regulation on the social and emotional self-regulation of children with ADHD.

\section{Conflicts of Interest}

The author declares no conflicts of interest regarding the publication of this paper.

\section{References}

[1] Westwood, P. (2007) Commonsense Methods for Children with Special Educational Needs. 5th Edition, Routledge Taylor \& Francis Group, London.

[2] Reid, R., Lienemann, T.O. and Hagaman, J.L. (2013) Strategy Instruction for Students with Learning Disabilities. Second Edition, Routledge, New York.

[3] Sroubek, A., Kelly, M. and Li, X. (2013) Inattentiveness in Attention-Deficit/ Hyperactivity Disorder. Neuroscience Bulletin, 29, 103-110.

https://doi.org/10.1007/s12264-012-1295-6

[4] Sagvolden, T., Johansen, B.E., Aase, H. and Russel, A.V. (2005) A Dynamic Developmental Theory of Attention-Deficit/Hyperactivity Disorder (ADHD) Predominantly Hyperactive/Impulsive and Combined Subtypes. Behavioral and Brain Sciences, 28, 397-419. https://doi.org/10.1017/S0140525X05000075

[5] Sideridis, G., Stamovlasis, D. and Antoniou, F. (2015) Reading Achievement Mas- 
tery and Performance Goal Structures among Student with Learning Disabilities: A Nonlinear Perspective. Journal of Learning Disabilities, 49, 631-643. https://doi.org/10.1177/0022219415576524

[6] Argyropoulos, V., Sideridis, G.D., Botsas, G. and Padeliadu, S. (2012) Assessing Self-Regulation in Individuals with Visual Impairments: Generality versus Specificity in Self-Regulatory Functioning. Assessment for Effective Intervention, 37, 171-182. https://doi.org/10.1177/1534508411406899

[7] Sideridis, G., Ageriadis, T., Irakleous, I., Siakali, M. and Georgiou, M. (2006) Do Students with and without Learning Disabilities Have Accurate Perceptions of Their Classrooms Motivational Climate? Insights on Learnings Disabilities, 3, 9-23.

[8] Wilkinson, A. (2010) Executive Functioning in Children with Asperger Syndrome, ADHD-Combined Type, ADHD-Predominately Inattentive Type and Controls. Journal of Autism and Developmental Disorders, 40, 1017-1027.

[9] Varsamis, P. and Agaliotis, I. (2015) Relationships between Gross and Fine Motor-Functions, Cognitive Abilities and Self-Regulatory Aspects of Students with Physical Disabilities. Research in Developmental Disabilities, 47, 430-440. https://doi.org/10.1016/j.ridd.2015.10.009

[10] Southall, C.M. and Gast, D.L. (2011) Self-Monitoring to Promote On-Task Behavior by Two High Functioning Boys with Autism Spectrum Disorders and Symptoms of ADHD. Research in Autism Spectrum Disorders, 8, 472-479. https://doi.org/10.1016/j.rasd.2014.01.007

[11] Lee, S.L., Schachar, R.J., Chen, S.X., Ornstein, T.J., Charach, A. and Barr, C. (2008) Predictive Validity DSM-IV and ICD-10 Criteria for ADHD and Hyperkinetic Disorder. Journal for Child Psychology and Psychiatry, 49, 70-78. https://doi.org/10.1111/j.1469-7610.2007.01784.x

[12] Eisenman, L.T. (2007) Social Networks and Careers of Young Adults with Intellectual Disabilities. Intellectual and Developmental Disabilities, 45, 199-208. https://doi.org/10.1352/1934-9556(2007)45[199:SNACOY]2.0.CO;2

[13] Schunk, D.H. and Zimmermann, B.J. (2008) Motivation and Self-Regulated Learning Theory, Research and Applications. Lawrence Erlbaum Associates, Mahwah.

[14] Mithaug, D.K. and Mithaug, D.E. (2003) Effects of Teacher-Directed versus Student Directed Instruction on Self Management of Young Children with Disabilities. Journal of Applied Behavior Analysis, 36, 133-136. https://doi.org/10.1901/jaba.2003.36-133

[15] Cleary, T.J., Plattern, P. and Nelson, A. (2008) Effectiveness of the Self-Regulation. Empowerment Program with Urban High School Student. Journal of Advanced Academics, 20, 70-107. https://doi.org/10.4219/jaa-2008-866

[16] Pelham, E.W., Fabiano, A.G. and Massetti, M.G. (2005) Evidence-Based Assessment of Attention Deficit Hyperactivity Disorder in Children and Adolescents. Journal of Clinical Child and Adolescent Psychology, 34, 449-476. https://doi.org/10.1207/s15374424jccp3403_5

[17] Antoniou, A.S., Geralexis, I. and Charitaki, G. (2017) Special Educators' Teaching Self-Efficacy Determination: A Quantitative Approach. Psychology, 8, 1642-1656. https://doi.org/10.4236/psych.2017.811108

[18] Bania, T.A., Antoniou, A.S., Theodoritsi, M., Theodoritsi, I., Charitaki, G. and Billis, E. (2019) The Interaction with Disabled Persons Scale: Translation and Cross-Cultural Validation into Greek. Disability and Rehabilitation, 1-8. https://doi.org/10.1080/09638288.2019.1643420

[19] Charitaki, G. (2015) The Effect of Ict on Emotional Education and Development of 
Young Children with Autism Spectrum Disorder. Procedia Computer Science, 65, 285-293. https://doi.org/10.1016/j.procs.2015.09.081

[20] Charitaki, G., Soulis, S.G. and Tyropoli, R. (2019) Academic Self-Regulation in Autism Spectrum Disorder: A Principal Components Analysis. International Journal of Disability, Development and Education.

https://doi.org/10.1080/1034912X.2019.1640353 